Mirai. Estudios Japoneses

ISSN-e: 1988-2378

http://dx.doi.org/10.5209/MIRA.57107

\title{
El patrimonio japonés a través del material turístico promocional: pasado y presente
}

\author{
$\mathrm{D}^{\mathrm{a}}$ Marisa Peiró Márquez ${ }^{1}$
}

Resumen: Esta investigación se centra en un variado corpus de carteles y folletos turísticos sobre Japón, destinados esencialmente al público foráneo, a través de los cuales examinaremos, valoraremos y cuantificaremos la manera en la que el patrimonio japonés — material e inmaterial — ha sido retratado por el negocio turístico y, por tanto, percibido por el público general. Para ello, ofreceremos algunos rasgos generales sobre las consideraciones del Patrimonio Cultural en Japón y las representaciones que del mismo se hace en los materiales de publicidad y difusión turísticos. Por último, reflexionaremos sobre las notables ausencias de ciertos elementos dentro de estos materiales.

Palabras claves: Turismo; arte gráfico; Japón; patrimonio cultural; representaciones culturales.

\section{[en] Japanese cultural heritage through tourism promotional material: past and present}

\begin{abstract}
In this paper we will study a broad corpus of Japan-themed tourist posters and brochures, principally intended for a foreign audience; through them we will examine, assess and evaluate the way Japanese cultural heritage - both tangible and intangible - has been portrayed by the tourism industry and, therefore, perceived by the general public. For such purpose, we will present some general features about considerations of Cultural Property in Japan and their representations in tourism promotional materials. Finally, we will address the remarkable absence of certain elements in these materials.
\end{abstract}

Keywords: Tourism; graphic art; Japan; cultural heritage; cultural depictions.

Sumario. 1. Introducción. 2. Aspectos generales sobre la historia del turismo en Japón y sobre la historia del patrimonio. 3. Principales elementos patrimoniales representados. 4. Una difusión del patrimonio limitada por sus ausencias y por sus consideraciones políticas. 4. Conclusiones.

Cómo citar: Peiró Márquez, M. (2017). El patrimonio japonés a través del material turístico promocional: pasado y presente (2017), en Mirai. Estudios Japoneses 1, 2017, 133-141.

\section{Introducción}

El cartel comercial constituye un tipo de ejercicio gráfico de carácter funcional clave dentro de la Historia de los medios de comunicación de masas y resulta inherente a la moderna industria turística. Junto a toda otra serie de materiales comerciales (como planos y folletos), el cartel turístico representa un tipo especial dentro de la categoría comercial, puesto que en su esencia se encuentran cuidadosamente en

\footnotetext{
1 Universidad de Zaragoza.

marisapeiromarquez@gmail.com
} 
armonía las tres funciones principales del cartel que ya señalase Enel'2: la comercial (pues nos vende la idea de un determinado viaje), la de propaganda (pues nos habla únicamente de sus bondades) y por supuesto, la cultural (pues nos informa de una realidad cultural y estética).

En la época del nacimiento tanto del cartel comercial como de la moderna industria turística, Japón se encontraba sumido en un constante y agitado proceso de modernización y occidentalización. A pesar de ello, algunos de los factores que más impresionaron al público extranjero - y por ello, potencial visitante del país - fueron los relacionados con la idea del Japón tradicional, una realidad que paradójicamente estaba en vías de desaparición. En el Occidente fascinado por el japonismo, sorprendían las imágenes de la rápida modernización del ejército o la Familia Imperial japonesa, pero las más demandadas eran aquellas que respondían a los usos y costumbres tradicionales — como las escenas de geishas y samuráis, que casi siempre se trataban de puestas en escena— ${ }^{3}$, al mismo tiempo que se produjo una fascinación por productos como quimonos, abanicos y estampas. Así, mientras que en el ámbito socioeconómico y cultural se observó una paradójica dialéctica entre los fervientes partidarios de la modernización a la occidental, tanto lingüística como temática, y el surgimiento de corrientes que favorecían un lenguaje nacional; el caso de las imágenes que aquí nos ocupan es sensiblemente diferente, ya que la tónica general, fue la reiteración de una serie de estilemas culturales entendidos inequívocamente como emblemas o símbolos culturales del Japón, que resultaban tan rápidamente identificables como poderosamente atractivos y evocadores tanto para el turista extranjero como para el viajero nipón.

Para nuestro análisis, estudiamos un corpus de obras producidas a lo largo de todo el siglo XX (esencialmente, entre los años 1910 y 1980, estando especialmente representadas las décadas centrales del siglo), compuesto esencialmente por carteles turísticos, folletos y anuncios publicados en revistas de carácter general. Aunque tomamos como referencia aquellos realizados para el público no japonés (es decir, escritos en lengua inglesa), analizaremos tanto los producidos por compañías japonesas como por extranjeras ${ }^{4}$. Las imágenes de Japón que se transmitieron a través de este tipo de objetos, promovieron una idea determinada de patrimonio cultural japonés, ayudando a su difusión, y constituyeron uno de los elementos principales para la promoción de una imagen cultural que, en un nivel generalista, todavía perdura.

A pesar de que los contenidos serán esencialmente los mismos a lo largo de las décadas, es interesante prestar atención a los diferentes lenguajes utilizados en su grafismo. Por una parte, aunque la mayoría de artistas fueron fieles al arte comercial

2 Para más información, véase los importantes estudios sobre el cartel EnEL, François (1974): El cartel. Lenguaje, funciones, retórica. Valencia: Fernando Torres Editor y BARnicoAT, John (2000): Los carteles. Su historia y su lenguaje. Barcelona: Gustavo Gili.

3 Para más información véase Cabrejas Almena, M. Carmen (2009): "Fotografía de ficción en Japón en el siglo XIX. Recreaciones de escenas para el mercado Occidental”. En: Anales de Historia del Arte, n. ${ }^{\circ}$ 19. Madrid, pp. 257-270.

4 Dentro de los materiales japoneses, analizaremos los producidos por la aerolínea de bandera Japan Airlines así como por las importantes navieras Nippon Yūsen Kaisha (N.Y.K.), Osaka Shōsen Kaisha (O.S.K.) y Toyo Kishen Kaisha, además de las realizadas por organismos municipales y estatales (Japan Tourist Bureau, Japanese Government Railways, Japan Travel Bureau), además de los materiales de algunos importantes hoteles. Dentro de las compañías extranjeras, analizamos materiales producidos por las europeas B.O.A.C. Air France, K.L.M., Swissair, Lufthansa y Scandinanvian Airlines, las asiáticas Air India y Thai Airways, las americanas Pan Am, American President Lines, T.W.A., Northwest Ailines, Canadian Pacific y Varig y la australiana Q.A.N.T.A.S. 
de cada momento (Art Nouveau, Art Deco, pero también shin-hanga, entre otros), mucho más interesante resulta, no obstante, el uso de lenguajes vernaculares como elemento patrimonial y para favorecer, con peor o mejor resultado, la identificación del contenido como japonés. Nos referimos, por supuesto, al uso (y abuso) de determinadas tipografías inspiradas en los sistemas de escritura japoneses, pero, sobre todo, a la interesante utilización de lenguajes que imitan las artes tradicionales japonesas, como la pintura yamato-e y, sobre todo, el grabado ukiyo-e; no es extraño ver carteles que directamente se apropian de fragmentos de obras ukiyo-e (tanto de artistas clásicos como de otros más recientes; por ejemplo, una obra de Uemura Shōen ha sido utilizada como cartel por varias aerolíneas), al tiempo que muchos otros diseñadores se han inspirado en el grabado japonés para ilustrar sus carteles sobre el país. Quizás por esto el lenguaje fotográfico hizo una aparición más tardía y limitada que en la parafernalia turística sobre otros países, a pesar de la temprana llegada de la fotografía a Japón. Por su carácter comercial, la mayoría de estos carteles son considerados como anónimos, aunque existen algunas excepciones, como pueden ser las valoradas obras del japonés Satomi Munetsugu ${ }^{5}$. Sin embargo, a partir de la década de los 1950 se produjo una mayor valoración del poster de autor, destacando a partir de este momento obras de diseñadores como Kuriyagawa Ken'ichi,, Tomoeda Otaro o Fukuda Shigeo.

\section{Aspectos generales sobre la historia del turismo en Japón y sobre la historia del patrimonio}

Antes de aventurarnos en el estudio del patrimonio japonés representado en el material turístico, cabe hacer una serie de consideraciones tanto sobre el desarrollo histórico del turismo en Japón como sobre las diferentes implicaciones morales y legales del concepto de patrimonio — natural, histórico y etnográfico — en el Japón unificado.

El nacimiento del turismo moderno en Japón tuvo lugar gracias a una serie de iniciativas estatales y a la apertura oficial de fronteras acaecida durante el periodo Meiji ${ }^{6}$. Mientras que los nipones dejaron de necesitar pasaporte para sus desplazamientos nacionales en 1870, la apertura a los extranjeros fue algo más gradual, estando limitada a determinados lugares y propósitos, lo que condicionaba la afluencia y la promoción turística.

En los años sucesivos, tendrá lugar la aparición de los modernos sistemas de transporte: de una, una extensa y compleja red de ferrocarriles que conseguirá vertebrar el país y hacer accesibles los destinos más alejados ${ }^{7}$; de otra parte, se generalizará la práctica del crucero, gracias a barcos cada vez más modernos y rápidos ${ }^{8}$, y

5 Para más información véase Peiró MÁrquez, Marisa (2016): "La imagen turística de Japón entre las dos Guerras Mundiales". En: Gómez Aragón, Anjhara (ed.): Japón y Occidente. El patrimonio cultural como punto de encuentro. Sevilla: Aconcagua Libros, pp. 685-694.

6 Para más información, véase: MARch, Roger (2007). "How Japan Solicited the West: The First Hundred Years of Modern Japanese Tourism". En: McDonnell, Ian (ed.) CAUTHE 2007: Tourism-Past Achievements, Future Challenges. Sydney: University of Technology Sydney.

7 La primera línea, que unió Tokio con Yokohama, se inauguró en 1872; durante la década de los 1880, el ferrocarril llegaría a Hokkaido, Shikoku y Kyushu.

8 Los turistas extranjeros llegaban al país a través puertos como Yokohama y Kobe, donde ya en 1870 recalaban las principales compañías de vapores; en 1875 se estableció entre Yokohama y Shanghái la primera línea regular 
aparecería la aviación comercial, que se consolidará definitivamente en las décadas centrales del siglo. En 1893 se fundaría la Kihin-Kai (Sociedad de Bienvenida), un organismo privado que centralizaba e institucionalizaba algunas de las prácticas turísticas más habituales, y en 1907 se nacionalizan y unifican las líneas ferroviarias japonesas, y se aprueba la Ley del Desarrollo de Hoteles, a partir de la cual la Compañía Ferroviaria Nacional construye una red de hoteles públicos a lo largo de las líneas ferroviarias del país. Las bases definitivas del actual turismo en Japón quedarán sentadas en 1964, cuando para la celebración de los Juegos Olímpicos de Tokio se levantaron las restricciones de entrada y movimiento de turistas.

En cuanto a las leyes destinadas a la protección del patrimonio en Japón ${ }^{9}$, puede afirmarse que este país fue uno de los pioneros en cuanto a la legislación - $\mathrm{y}$ aplicación de la misma - de los bienes culturales y naturales, adelantándose en sus medidas y su amplitud a las de muchos países europeos - como España- e incluso a la UNESCO, especialmente en lo que se refiere a figuras como el patrimonio etnográfico $^{10}$ o el paisaje ${ }^{11}$ y los monumentos naturales. Así, mediante la Ley para la protección del Patrimonio Cultural, promulgada en 1950, y que sigue en vigor, se protegieron muchos aspectos que no fueron tenidos en cuenta en Occidente hasta varias décadas después, especialmente en lo que afecta a elementos ligados a la sensibilidad artística tradicional, como el sentido del paisaje y las expresiones de vida tradicionales $^{12}$.

Así, el texto de esta ley define seis tipos de Patrimonio Cultural (Tangible, Intangible, Etnográfico, Monumentos, Paisajes Culturales y Grupos de edificios tradicionales), según los cuales un nutrido grupo de elementos es susceptible de ser Patrimonio Cultural, siempre que tenga un valor histórico, científico y/o artístico significativo para Japón: edificios de todo tipo, yacimientos arqueológicos de todo tipo, pintura, artes aplicadas, obras de caligrafía, libros clásicos, documentos antiguos, fuentes históricas, pero también música y artes escénicas, costumbres que afectan a la vestimenta, la vivienda, las profesiones, la alimentación y las creencias religiosas y sus festividades. También se protegen animales, plantas y zonas geológicas y minerales, así como "paisajes culturales" creados por los modos de vida tradicional". Es decir, la Ley considera Patrimonio Cultural una variadísima serie de elementos, muchos de los cuales serán reproducidos en la cartelería turística, como veremos a continuación.

de pasajeros de Japón. La Nippon Yūsen Kaisha, fundada en 1885, controlaría en los años venideros la mayor parte del flujo turístico del país.

9 Un conciso repaso a los principales hitos en cuanto al reconocimiento del patrimonio histórico —en este caso, arqueológico - japonés puede leerse en ABAD DE Los SANTos, Rafael (2016): "El patrimonio arqueológico y su conservación en Japón". En: Gómez Aragón, Anjhara (ed.): Japón y Occidente. El patrimonio cultural como punto de encuentro. Sevilla: Aconcagua Libros, pp. 257-264.

10 No fue hasta 1968 cuando en los documentos programáticos de la UNESCO aparecerá la recomendación de conservar los bienes culturales que atañen a la cultura tradicional y se de la voz de alarma ante su incipiente desaparición. Agudo Torrico, Juan (2016): “La valoración del patrimonio inmaterial en España y Japón. Una breve reflexión comparativa”. En: Gómez Aragón, Anjhara (ed.): Japón y Occidente. El patrimonio cultural como punto de encuentro. Sevilla, 26 al 29 de marzo de 2014. Sevilla: Aconcagua Libros, p. 240.

11 Ya en 1919 se promulgó una ley que además incluía en los elementos a proteger las "localizaciones paisajísticas" y monumentos de carácter natural, como el Monte Fuji. ABAD DE LOS SANTOS, Rafael (2016): "El patrimonio arqueológico...", op. cit., p. 260.

12 Agudo Torrico, Juan (2016): “La valoración del patrimonio...”, op. cit., p. 238.

$13 \mathrm{ttp} / / /$ www.unesco.org/culture/natlaws/media/pdf/japan/japan_lawprotectionculturalproperty_engtof.pdf [Consulta: 03-09-2016] (traducción de la autora) 


\section{Principales elementos patrimoniales representados}

En los diferentes materiales publicitarios aparecen constantemente repetida toda una serie de elementos que son considerados como principales representantes del patrimonio cultural japonés. Básicamente, los mismos pueden dividirse en categorías: los que hacen referencia o proponen la visita a sitios reales, tanto de manera exclusiva como en combinados, y los que incluyen una serie de elementos patrimoniales, pero no constituyen una referencia real ni física. Dentro de las dos categorías existen, por supuesto, una serie de referencias explícitas hacia los diferentes medios de transporte, utilizadas tanto para sugerir la idea de viaje como para reforzar el concepto de marca, en otros casos; así, no faltarán representaciones de barcos y aviones - las de trenes son mucho menos frecuentes-, especialmente en la publicidad del periodo de Entreguerras.

Dentro de los materiales que hacen referencia a lugares reales, tendrán una gran importancia no solo los monumentos históricos, sino también los paisajes culturales y naturales. En este sentido es promocionado, por ejemplo, Nikkō — uno de los hitos principales del turismo desde época Meiji- ${ }^{14}$, tanto en su calidad de santuario (una de cuyas puertas, Yōmeimon, es representada con gran detalle en numerosos carteles) como de parque natural. Algo parecido le sucede a Nara, cuyo principal elemento representativo en la cartelería son los —anteriormente divinos, ahora meramente patrimoniales - ciervos del Parque de Nara, cuya representación se combina con diferentes elementos naturales y humanos, como abundantes linternas de piedra o representaciones del Hōryū-ji. La misma consideración podría hacerse sobre las abundantes representaciones de la isla de Miyajima — otro de los destinos habituales del turista Meiji- y del famoso torii en el agua del santuario de Itsukushima. La representación de muchas otras ciudades suele estar limitada a uno o dos elementos representativos de las mismas, como sucede con el Kinkaku-ji de Kioto, los daibutsu de Kobe - también promocionada como ciudad de compras-y, sobre todo, de Kamakura ${ }^{15}$, o los castillos de Osaka, Nagoya y Hirosaki. No obstante, Tokio aparece representado más por su nombre que por elementos patrimoniales concretos, y sus materiales promocionales contienen más referencias a las novedades (el metro, el antiguo Hotel Imperial) que al antiguo patrimonio de Edo. Asimismo, se promocionan otros destinos, como Yokohama, Izu, Kyushu y Shikoku, Okayama, Karuizawa o Matsushima, entre los que sobresalen con fuerza elementos naturales como el Monte Fuji y lagos como el Towaka y Yanamaka. Por supuesto, el omnipresente Fuji es uno de los elementos más representados, ya que funciona a la vez como símbolo y como referencia real, representada tanto como telón de fondo de muchos destinos turísticos tanto como en solitario.

Muchas de las representaciones del Monte Fuji poseerán cierta tendencia a la abstracción, algo que comparte con las representaciones de muchos elementos vegetales - copiando o imitando, en muchas ocasiones, los tradicionales mon-y con las representaciones del Sol Naciente, muy habituales hasta la derrota en la Segunda Gue-

14 Para más información, véase BArlés BAguena, Elena (2016): "Nikkō, "la Alhambra japonesa" en la mirada de los viajeros occidentales en el periodo Meiji”. En: Gómez Aragón, Anjhara (ed.): Japón y Occidente. El patrimonio cultural como punto de encuentro. Sevilla: Aconcagua Libros, pp. 615-625.

15 El Gran Buda de Kamakura fue uno de los iconos más mediáticos del recién abierto Japón. Para más información, véase Almazán Tomás, Vicente David (2013): "La construcción visual de Japón desde Occidente: el Gran Buda de Kamakura como monumento turístico". En: GARCÉs GArcía, Pilar / Terrón BArbosa, Lourdes (coord.): Itinerarios, viajes y contactos Japón-Europa. Berna: Peter Lang Publishing Group, pp. 49-64. 
rra Mundial. Dentro de las referencias genéricas, predominan las representaciones de templos y jardines (habitualmente, con elementos como pagodas, torii y linternas de piedra) a veces con lagos o estanques y juncos, casi siempre acompañados de árboles en flor como cerezos o glicinias; el crisantemo, flor emblemática por excelencia, ha perdido en los últimos años presencia frente al bonsái. Otros elementos, como abanicos, sombrillas y farolillos de papel, aparecen también habitualmente representados, en muchas ocasiones acompañado a uno de los motivos principales de la cartelería turística — de Japón y de prácticamente cualquier otro lugar —: las mujeres. Siguiendo los cánones de belleza a la moda, una gran cantidad de carteles representan mujeres bellas — geishas y no_- ataviadas siempre a la manera tradicional, como si todavía esta fuera la vestimenta diaria de la mujer japonesa. Representadas con mayor o menor sensualidad, suelen estar realizadas en un tono más sentimental que sugerente, apelando más a un sentido nostálgico que sexualizado. Lo mismo sucede con las habituales figuras de niños y fiestas infantiles, que pueblan una gran cantidad de carteles, así como lo hacen otros elementos relacionados con la infancia, como cometas, koinobori o gosho ningyo. También el patrimonio inmaterial cuenta con sus representaciones, aunque estas son más recientes en el tiempo: las máscaras del nō y los coloridos vestidos y maquillajes del kabuki son los más son los elementos más habituales, aunque no los únicos.

Sorprende no encontrar más referencias — más allá de alguna catana y castilloa la antigua cultura samurái, dado que este ha sido uno de los aspectos de la historia japonesa que más ha calado en el exterior. Lo mismo puede decirse de las representaciones de la gastronomía y de las artes marciales (apenas hay, por ejemplo, algún luchador de sumo), aunque debemos tener en cuenta que estas han alcanzado el pleno reconocimiento internacional hace apenas algunas décadas.

\section{Una difusión del patrimonio limitada por sus ausencias y por sus consideraciones políticas}

Pero, si Japón tiene una de las nociones legales más amplias de patrimonio cultural, ¿cómo pueden limitarse las representaciones a una serie de elementos arquetípicos? ¿Por qué insistir en nuevas versiones de las mismas geishas, pagodas y jardines? ${ }^{16}$ A nuestro parecer, existen dos razones muy claras: la necesidad de simplificar el mensaje a transmitir para ganar efectividad en su transmisión y, por otra parte, la voluntad de acotar y dirigir el mensaje.

Así, la esquematización y reiteración del mensaje no es una particularidad del caso japonés, y resulta tan esperada como deseable ${ }^{17}$, que responde además a un caso claro de oferta-demanda ${ }^{18}$. No obstante, su otredad viene a ser constantemente

16 "Geishas, pagodas y jardines" es precisamente el nombre de un texto de David Almazán que analiza este fenómeno concretándolo con el caso de los álbumes fotográficos sobre Japón. Para más información, véase ALMAZÁN TomÁs, Vicente David (2011): “Geishas, pagodas y jardines: los álbumes de estampas y albúminas como souvenirs para los viajeros en Japón del siglo XIX”. En: Cabañas Bravo, Miguel / López-Yarto Elizalde, Amelia / Rincón GARCía, Wifredo (coord.), El arte y el viaje. Madrid: CSIC, pp. 643-658.

17 Barnicoat, John (2000): Los carteles..., op. cit., p. 81.

18 "El turista busca la caricatura: las agencias de viaje locales y los ministerios de turismo extranjeros están prestos a obligarle a ello. Al turista rara vez le gusta el auténtico producto (que para él es a menudo inteligible) de la cultura extranjera; prefiere sus propias expectativas provincianas. (...) El turista americano en Japón busca me- 
recordada y amplificada dentro de la construcción de un mundo iconográfico japonés de cara a una esfera pública y popular. Pero, por otra parte, y mucho más importante, no debemos olvidar que:

El concepto de patrimonio cultural (antes tesoros nacionales) tiene en origen unas connotaciones fundamentalmente políticas, vinculadas al desarrollo de los Estadosnaciones desde el siglo XIX. Los referentes seleccionados de nuestro entorno cultural como bienes patrimonializados no tienen sino la función de mostrar (a los demás y a las propias comunidades), de forma sincrética y simbólica, a un nosotros concreto ${ }^{19}$.

Así pues, el proceso patrimonialista forma parte de la memoria construida $-\mathrm{y}$ selectiva - con la que se define la historia. Las consideradas tradiciones son, según Abad de los Santos:

"[...] una memoria viva (también permanentemente revisable y no menos cargada de ideología que la interpretación de la historia) que permite articular, dotándolo de continuidad, el presente con el pasado; y que va a ser determinante en el discurso patrimonial relacionado con la cultura inmaterial y, en general, con el denominado patrimonio etnológico vinculado con los modos de vida en uso de determinadas colectividades ${ }^{20}$.

Aunque el hallazgo, manipulación y conservación del patrimonio arqueológico fue sujeto de legislación estatal desde la década de 1870, la consideración - tanto legal como informal - de los materiales de diferentes periodos históricos variaba considerablemente, respondiendo "a una evidente intencionalidad política y debe ser comprendida dentro del nuevo contexto ideológico surgido con la Restauración Meiji" 21 . Así, los "tesoros" conservados en templos eran automáticamente integrados al discurso historicista japonés, tal como sucedía con los materiales relativos a los kofun - solo que con estos se dificultaba la investigación con el fin de evitar cualquier discrepancia con la historia oficial de la Casa Imperial japonesa - pero por otro lado, los "artefactos de la Edad de Piedra" (es decir, vinculados a lo que ahora conocemos como periodo Jōmon y a parte del Yayoi) no fueron considerados como japoneses ni integrados dentro del discurso histórico - y, por tanto, patrimonialístico - hasta época muy reciente; no debemos olvidar que algunos pioneros de la arqueología japonesa, como Edward S. Morse, atribuyeron el periodo lítico de Japón a un pueblo de primitivos salvajes sin ninguna relación con los japoneses ${ }^{22}$.

Precisamente, estas son las grandes ausencias patrimoniales de la cartelería turística sobre Japón. Mientras que elementos de relativa antigüedad son asimilados dentro del discurso histórico y turístico ${ }^{23}$, se omite por completo cualquier referencia a la prehistoria japonesa, ya sea por precaución — caso de las polémicas relativas a

nos lo que es japonés que lo que es ajaponesado". Boorstin, Daniel J. (2012): The Image: A Guide to PseudoEvents in America. Nueva York: Random House LLC.

19 Agudo Torrico, Juan (2016). “La valoración del patrimonio...”, op. cit., p. 236.

20 Ibid., P. 237.

21 ABAd de los Santos, Rafael (2016): “El patrimonio arqueológico...”, op. cit., p. 258.

22 Ibid., pp. 257-259.

23 A muchos de los lugares representados en los carteles, como los santuarios de Nikkō o Miyajima, se les atribuye fundación en los periodos protohistóricos de Japón — Asuka y Nara-, si bien sus elementos principales datan de muchos siglos más tarde y pertenecen a periodos inequívocamente japoneses de la historia. Por otro lado, no debemos olvidar las diferentes nociones de autenticidad y originalidad propias de la conversación japonesa. 
la excavación de los kofun - o por la no asimilación de determinadas producciones (dōtaku, dogū y otras producciones de la cerámica Jomōn) como propias dentro del discurso unitario nacionalista de la cultura japonesa.

En este mismo sentido puede comprenderse la ausencia de las diferentes minorías étnicas, lingüísticas y religiosas de los materiales turísticas. Mientras que se fomenta la visita a determinados lugares de Japón - como Sado - mediante la representación pintoresquista de su folclore, la negación de una población y una cultura japonesa no Yamato-descendiente es bastante explícita. Aunque la ausencia de representaciones de determinados grupos demográficos históricos de Japón (emishi, hayato, kumaso...) es comprensible, las minorías actuales (ainus, ryukyuenses...) no cuentan con prácticamente ninguna representación, incluso cuando sus lugares de origen son frecuentemente mencionados, se alude únicamente a sus condiciones climatológicas y naturales. Tampoco están representados otros elementos derivados de diferentes tradiciones históricas y religiosas — como las artes namban-, que sí cuentan con un gran reconocimiento internacional, promoviéndose la idea de un Japón tradicional ligado meramente a los ritos sintoístas, con ciertas concesiones al budismo.

Por último - aunque esto mismo sucede dentro de las tradiciones patrimoniales de muchos otros países - los elementos recientes en el tiempo todavía no han sido integrados dentro del discurso propagandístico. Mientras que buena parte la arquitectura de los periodos Meiji, Taisho y Shōwa no logra alcanzar un efectivo reconocimiento, algunos elementos de la cultura contemporánea de Japón —como la moda urbana, el manganime y los videojuegos - sí han sido efectivamente utilizados, dentro de iniciativas de soft power tan relevantes como Cool Japan ${ }^{24}$, pero para ello ha habido que esperar hasta esta última década.

\section{Conclusiones}

En definitiva, como hemos podido ver a lo largo de estas páginas, las imágenes patrimoniales de Japón reproducidas en los materiales turísticos de la mayor parte del siglo XX son arquetípicas aunque variadas, si bien se limitan al arte y la cultura de un Japón centralizado y unificado, reiterando el discurso — casi sin excepción- de tradición y unidad cultural que ha perdurado durante los últimos 150 años. Así, se ignora la representación de las minorías étnicas, lingüísticas y religiosas del país, así como los periodos prehistóricos de Japón. A nivel turístico, el desaprovechamiento de lo vernáculo y de lo arqueológico - uno de los principales argumentos de autoridad en los materiales turísticos de muchos otros países - no resulta demasiado conveniente y parece incomprensible a nivel comercial si no se tiene en cuenta dicho discurso. No obstante, es importante hacer notar que, a pesar de lo arquetípico y estereotipado del contenido de buena parte de los materiales analizados, este es

24 El término Cool Japan fue acuñado en 2002 por Douglas McGray para referirse a la creciente ola neojaponista de admiración por los productos y valores japoneses. Poco tiempo después, el gobierno japonés decidió utilizar el término como estrategia de Nation Branding. Dentro de la promoción Cool Japan se encuentran seis sectores clave: la moda (sobre todo urbana, femenina y/o juvenil), las manufacturas, la alimentación, las industrias de contenido (con especial importancia del manga y el anime), el turismo y el hogar. Para más información, véase GonzÁlez Represa, María Cristina (2016): “Japón, una estrategia política de marketing, soft power y Nation Branding del caso Cool Japan”. En: Gómez ArAgón, Anjhara (ed.): Japón y Occidente. El patrimonio cultural como punto de encuentro. Sevilla: Aconcagua Libros, pp. 303-312. 
producido tanto por instituciones gubernamentales y compañías japonesas como por empresas extranjeras, para las que lejos de intenciones estrictamente ideológicas prima un interés comercial.

Así, podemos concluir que los materiales turísticos analizados prolongan la construcción artificial de una cultura unitaria japonesa hasta las décadas finales del siglo XX, promoviendo el mismo Japón de geishas de abanico y sombrilla, pagodas, castillos, cerezos en flor y Monte Fuji que ya era ampliamente comercializado en las décadas finales del siglo XIX. Aunque se incorporaron otras representaciones variadas ligadas a las tradiciones y al patrimonio inmaterial (como las relacionadas con las artes escénicas o las festividades infantiles), son muy pocas las que hacen referencia a otros elementos tan representativos como la gastronomía o las artes marciales, algo incomprensible teniendo en cuenta el reconocimiento con que estas manifestaciones cuentan fuera del país. Por último, la tecnología y otros elementos culturales del Japón más contemporáneo igualmente atrayentes han permanecido ausentes hasta época recentísima, no aprovechando correctamente el neojaponismo aparecido. 